\title{
Deformação das rochas siliciclásticas paleoproterozoicas do Grupo Araí como exemplo das reativações de falhas do embasamento, Serra do Tepequém, Roraima, norte do Brasil
}

\author{
Lucindo Antunes Fernandes Filho ${ }^{1,2,3 *}$, Roberto Vizeu Lima Pinheiro ${ }^{2}$, \\ Werner Truckenbrodt ${ }^{2,3}$,Afonso César Rodrigues Nogueira ${ }^{2,3}$
}

\begin{abstract}
Resumo As rochas siliciclásticas da Serra do Tepequém são correlacionadas aos Grupos Araí e Suapi, pertencentes ao Supergrupo Roraima de idade paleoproterozoica. A análise estrutural destas rochas revelou que o acamamento exibe arranjos com mergulhos preferencialmente para SE e NW, individualizados em domínios limitados por zonas de falhas oblíquas sinistrais com rejeitos normais e inversos, com direção NE-SW. Essa estruturação é formada por dobras forçadas quilométricas do tipo kink bands e chevrons. O novo arcabouço geométrico observado é característico de um ambiente de deformação de nível crustal raso a médio. A história tectônica é controlada por reativações dos planos de fraqueza preexistentes nas tramas antigas, dúcteis, do embasamento. Esse modelo diverge dos regionais prévios para a região, os quais consideram as dobras existentes como produtos de ambiente dúctil sob tectônica colisional. Os resultados evidenciam a importância da presença de estruturas antigas do embasamento, relacionado ao Escudo das Guianas, como controladoras da geometria das rochas da Serra do Tepequém, em ambiente rúptil.
\end{abstract}

Palavras-chave: Serra do Tepequém; paleoproterozoico; Grupo Arai; análise estrutural; dobras kink bands.

\begin{abstract}
Deformation of paleoproterozoic siliciclastic rocks of the Arai Group as an example of basement fault reactivations, Serra do Tepequém, Roraima, Northern Brazil. Serra do Tepequém region comprises paleoproterozoic siliciclastic rocks from Araí and Suapi Groups, which are part of Roraima Super-group. Field data indicate that bedding is dipping towards SE and NW in different domains limited by NE-SW sinistral oblique faults with both normal and also reverse displacements. The structural setting is formed by regional scale forced folds represented by kilometre scale kink bands and chevron folds. The proposed framework is compatible with upper-to-middle crustal level. The studied faults were controlled by reactivation of early ductile basement fabric. These findings differ from previous regional models, based on folding under ductile conditions related to colisional tectonics. Results evidence the importance of Guiana Shield early basement structures in controlling the geometry of the brittle structures, which were seen on the cover rocks of Serra do Tepequém.
\end{abstract}

Keywords: Serra do Tepequém; paleoproterozoic; Arai Group; structural analysis; Kink band folds.

\section{INTRODUÇÃO O Escudo das Guianas} (EG) constitui a porção Norte do Cráton Amazônico, que representa uma extensa unidade tectônica localizada no Norte da América do Sul, no Estado de Roraima, Norte do Brasil (Almeida $\&$ Hasui 1984). Este escudo possui um dos maiores registros contínuos de rochas pré-cambrianas na América do Sul. Apesar disso, ainda são necessários estudos mais detalhados para o entendimento adequado de sua evolução geológica, atualmente baseada apenas em trabalhos de escala regional. Enquanto a maioria dos trabalhos de Geologia Estrutural na região enfoca as rochas do embasamento (Gibbs \& Barron 1993, Lima et al. 1982, Costa et al. 1991, Fraga et al. 1998, Reis et al. 2003), são escassos os estudos envolvendo as coberturas vulcanossedimentares (Braun 1973, Pinheiro et al. 1990, Fraga 1999).

As pesquisas nessas coberturas são predominantemente de cunho litoestratigráfico, concentradas principalmente em áreas do Bloco Pacaraíma (BP), no qual ocorre exposição contínua dos depósitos siliciclásticos do Supergrupo Roraima. Os diversos fragmentos destas coberturas, expostos em morros testemunhos, são ainda pouco estudados do ponto de vista tectônico. A Serra do Tepequém, localizada ao Norte do Estado de Roraima, com aproximadamente $90 \mathrm{~km}^{2}$ de extensão e altitude entre 550 e $1.100 \mathrm{~m}$, é uma destas feições isoladas, e é o objeto deste estudo. A serra, particularmente, representa um testemunho de rochas paleoproterozoicas do Supergrupo Roraima, assentadas

\footnotetext{
${ }^{1}$ Departamento de Geociências, Universidade Federal do Amazonas - UFAM, Manaus (AM), Brasil. E-mail: 1fernandesfilho@gmail.com ${ }^{2}$ Instituto de Geociências, Universidade de Federal do Pará - UFPA, Belém (PA), Brasil. E-mail: vizeu@ufpa.br

${ }^{3}$ Programa de Pós-Graduação em Geologia e Geoquímica - UFPA, Belém (PA), Brasil. E-mails: trucken@ufpa.br, anogueira@ufpa.br

*Autor correspondente
} 
discordantemente sobre as rochas vulcânicas do Grupo Surumú (Fig. 1). As rochas da sucessão sedimentar da serra são correlatas aos depósitos dos Grupos Arai e Suapi, unidades basais do Supergrupo Roraima, e encontram-se parcialmente deformadas (Fernandes Filho 1990 \& Truckenbrodt et al. 2008). A estruturação dessas rochas tem sido considerada como produto de deformação sinsedimentar ou atectônica (Fernandes Filho 1990), associada à tectônica compressiva regional (Reis \& Carvalho 1996, Fraga et al. 1994A, Fraga 1999), ou causada por blocos falhados associados a intrusões ígneas (Borges \& D'Antona 1988). Até o momento, o modelo de dobras holomórficas, cilíndricas e de escala quilométrica tem persistido na maioria dos estudos estruturais desta localidade. Neste trabalho, a análise geométrica-estrutural das rochas da Serra do Tepequém, em combinação com a interpretação dos produtos de sensores remotos e, principalmente, no estudo de afloramentos, permitiu a indicação de um arranjo geométrico relacionado à rotação de camadas como resultado da reativação das zonas de falhas do embasamento, no EG.

\section{CONTEXTO GEOLÓGICO}

Aspectos tectonoestruturais A região da Serra do Tepequém, localizada no Centro-norte do EG, faz parte de domínios das províncias geocronológicas Maroni-Itacaiunas (2,2 a 1,95 Ga; Tassinari \& Macambira 2004) e Tapajós-Parima (1,95 a 1,80 Ga; Santos et al. 2000), bem como do domínio litoestrutural Urariquera (Reis et al. 2003). Essa região é marcada por rochas vulcânicas ácidas a intermediárias do Grupo Surumu, de 2,0 a 1,95 Ga (Tassinari et al. 2000 \& Schobbenhaus et al. 1994), sobrepostas pela sucessão sedimentar do Supergrupo Roraima.

Tassinari et al. (2000) sugerem idade anterior a 2,3 Ga para o embasamento metamórfico de Roraima, constituído por terrenos de alto grau metamórfico da Província Maroni-Itacaiúnas, e interpretam o Bloco Roraima como uma bacia estável tipo
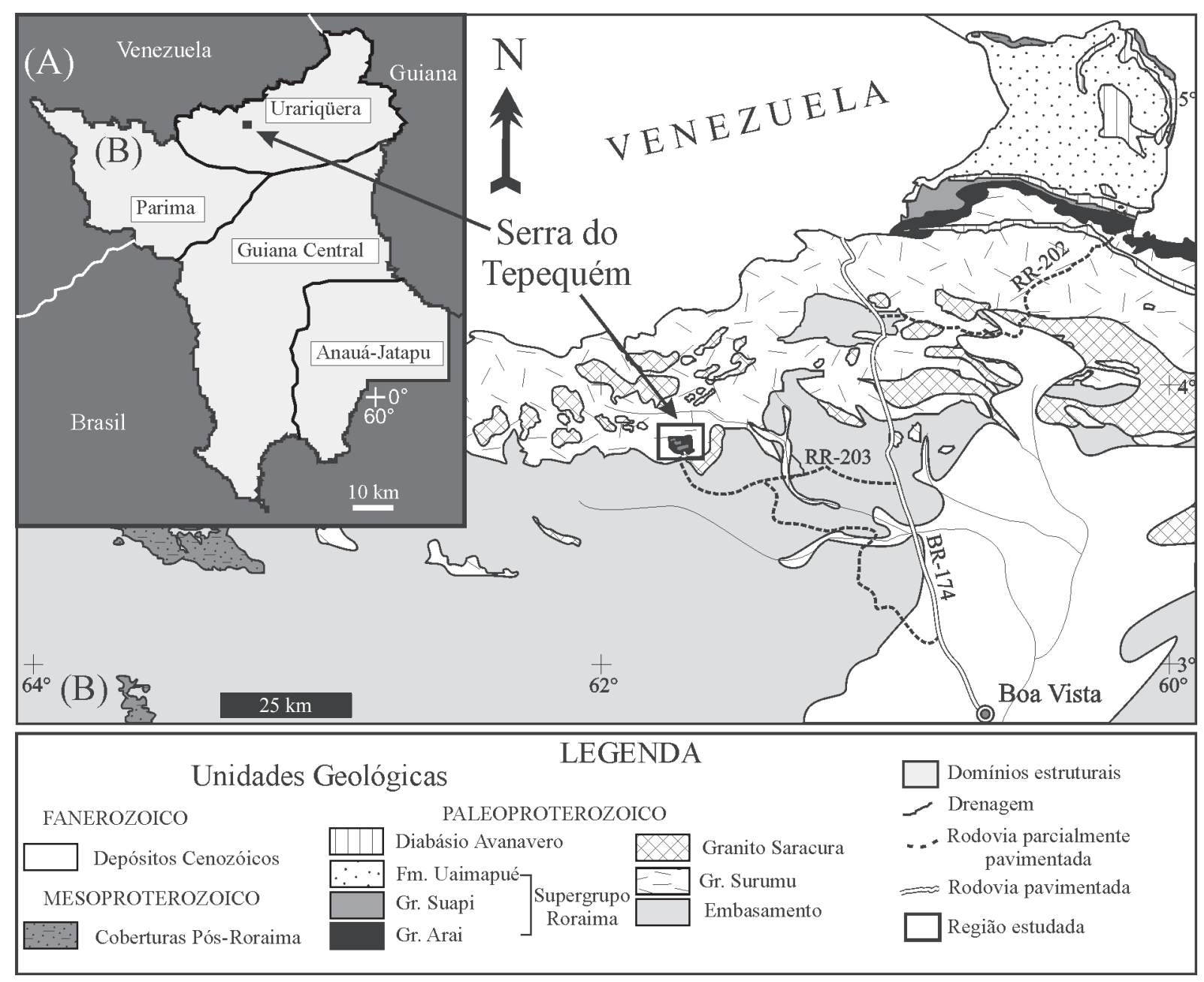

Figura 1 - (A) Dominios estruturais do Estado de Roraima e (B) mapa geológico simplificado da região Norte do Estado de Roraima com destaque para a Serra do Tepequém (modificado de Fraga et al. 1999). 
foreland, marginal ao Cinturão Maroni-Itacaiúnas. O domínio Urariquera, ao Norte do Estado de Roraima, é caracterizado por lineamentos WNW-ESE a E-W e NW-SE, sendo este limitado pelo domínio Parima a Oeste e pelo Cinturão Guiana Central ao sul (Fig. 1A), com importantes trends estruturais E-W, WNW-ESE e NW-SE (Fig. 2). A parte Sul do domínio Urariquera é caracterizada por rochas metassedimentares e metavulcânicas do Grupo Cauarane, enquanto que, na parte ao Norte, ocorrem rochas vulcânicas do Grupo Surumu, granitos das Suítes Pedra Pintada e Saracura, bem como depósitos sedimentares do Supergrupo Roraima (Figs. 1B e 2).

Nas últimas décadas, o Cinturão Guiana Central (CGC), com orientação NE-SW, tem sido considerado como a principal feição tectônica paleoproterozoica

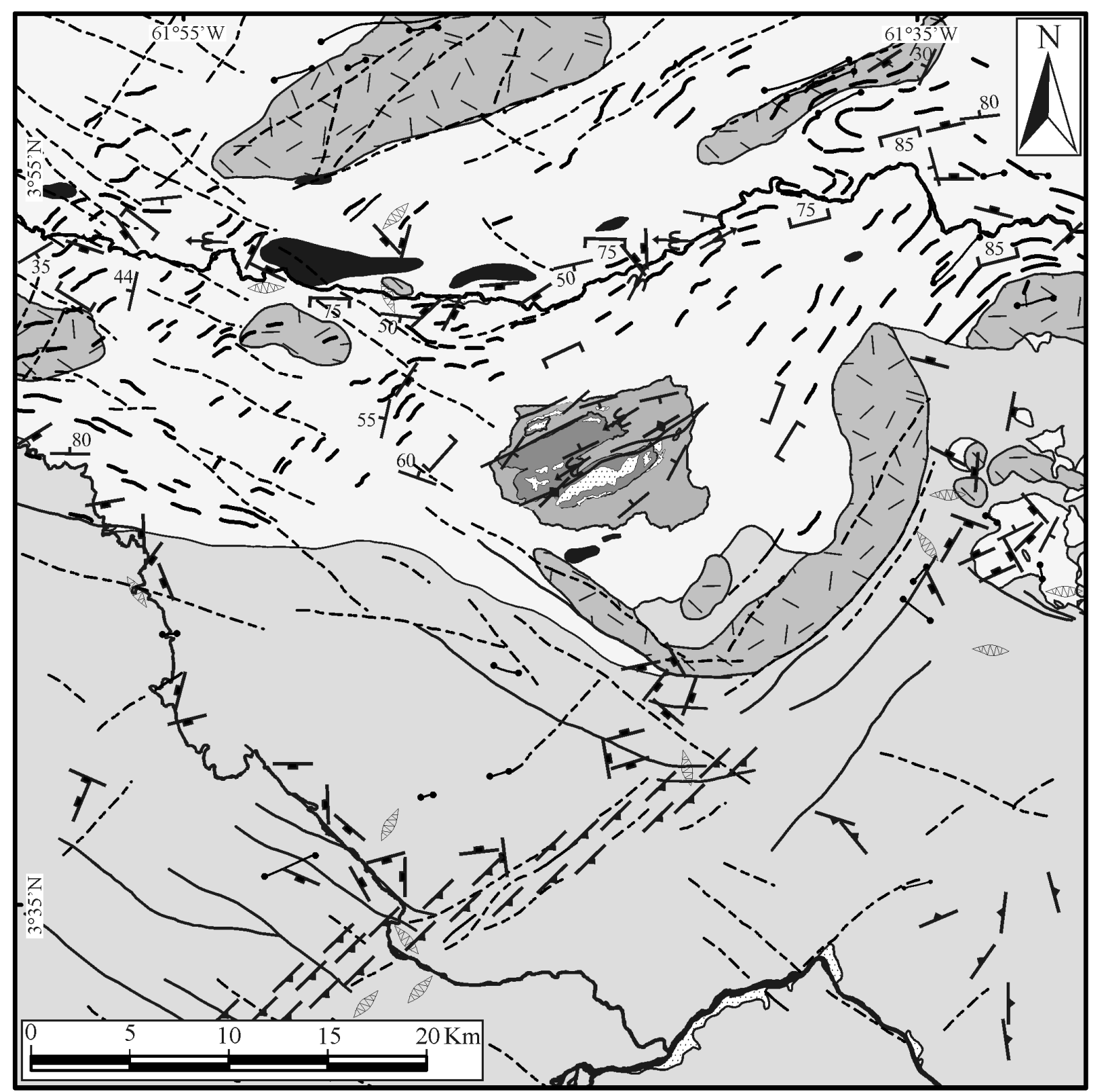

UNIDADES GEOLÓGICAS

ESTRUTURAS
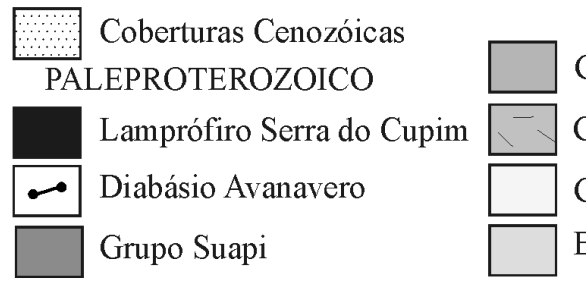
Grupo Arai
Granito Saracura
Grupo Surumu
Embasamento

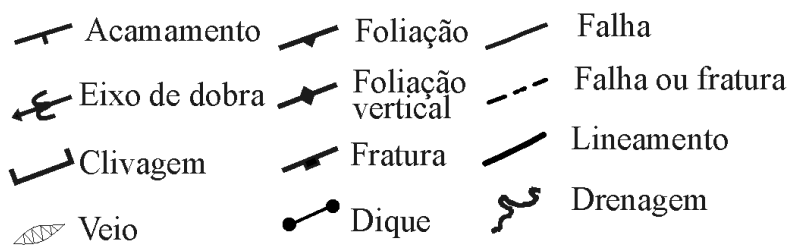

Figura 2 - Mapa geológico simplificado da região da Serra do Tepequém, representando parte de uma cobertura sedimentar paleoproterozoica assentada sobre rochas vulcânicas do Grupo Surumu (modificado de Fraga et al. 2010). 
na região Centro-norte do EG (Gibbs \& Barron 1993, Lima et al. 1982, Costa et al. 1991, Fraga et al. 1998, Reis et al. 2003). Recentemente, nesta mesma região, o CGC foi reinterpretado como uma megaestrutura sinuosa NW-SE/NE-SW/NW-SE, denominada Cinturão Cauarane-Coeroeni (CCC) (Fraga 2002, Fraga et al. 2008, Fraga et al. 2009), retomando ideias de trabalhos anteriores (Barron 1966, Kroonenberg 1976, Berrangé 1977). Segundo Fraga et al. (2008), durante o desenvolvimento deste cinturão ocorreu o principal evento tectonotermal $(\sim 2,0 \mathrm{Ga})$ responsável pela geração de importantes estruturas dúcteis de alta temperatura nas rochas do embasamento, que foram posteriormente reativadas. O Episódio K'Mudku ( 1,1 a 1,2 Ga; Barron 1966), como evento deformacional subsequente, afetou, também, esta parte do escudo. Vários autores referem-se a este episódio como sendo responsável pela formação de importantes estruturas, tais como: dobras, falhas, fraturas e zonas de cisalhamento presentes nas rochas deste segmento (Borges \& D'Antona 1988, Fernandes Filho 1990, Fraga \& Reis 1994 a e b, Fraga 2010).

Borges \& D'Antona (1988) descreveram as rochas da Serra do Tepequém como um sinclinório assimétrico de direção NE-SW e caimento para SW, cortado por fraturas NW-SE e NE-SW e, subordinamente, NNE-SSW, NNW-SSE e E-W. Para tais autores, as dobras, cujos eixos se dispõem paralelos e coincidentes às falhas, foram classificadas como longitudinais. Fernandes Filho (1990) identificou na serra um sinclinório, subdividido em braquissinclinais e braquianticlinais assimétricos, abertos, de direção geral $\mathrm{N} 75^{\circ} \mathrm{E}$, cuja origem foi atribuída à compactação diferencial. Este mesmo autor descreveu também zonas de falhas marcadas por foliação cataclástica, preferencialmente subvertical, de direção geral N65 E, como produto de tectonismo regional, com encurtamento próximo a $\mathrm{N} 65^{\circ}-75^{\circ} \mathrm{W}$.

Fraga et al. (1994 a e b) descreveram a Serra do Tepequém como formada por camadas dobradas em sinformais e antiformais suaves, com eixos na direção E-W e ENE-WSW, sem desenvolvimento de foliação. Essa estruturação foi relacionada à reativação das falhas normais, denominada "Bacia Tepequém”. Fraga \& Reis et al. (1994a) referem-se ao Episódio K'Mudku como compressivo, responsável pelo desenvolvimento dos feixes de cavalgamentos de direção E-W, ENE-WSW, os quais imprimem texturas miloníticas nas rochas vulcânicas adjacentes e clivagens nas rochas sedimentares da serra. Com base no mapeamento geológico, Fraga (2010) sugeriu três fases das reativações de estruturas antigas do embasamento, tendo a terceira em torno de 1,2 Ga, controlado à evolução dos dobramentos, encontrados nas rochas vulcânicas do Grupo Surumu e sedimentares da Serra do Tepequém, por meio da atuação de tectônica transpressional com compressão principal na direção N15W.

\section{Litoestratigrafia do Grupo Araí Bouman (1959)} utilizou, pela primeira vez, a denominação Membro Araí para agrupar rochas constituídas preferencialmente de quartzo-arenitos, com matriz micromicácea, intercalados a conglomerados e siltitos. A seção-tipo da unidade foi definida na serra homônima, no BP, próximo da fronteira Brasil e Venezuela. Montalvão et al. (1975) propuseram a elevação deste membro à categoria de Formação Araí, em concordância com Reid (1972). Em estudos realizados nos depósitos da Serra do Tepequém, Borges \& D'Antona (1988) correlacionaram estas rochas com a Formação Araí, subdividindo-as nos membros Paiva, Funil e Cabo Sobral. Fernandes Filho (1990), por sua vez, subdividiu a sucessão nos Membros Inferior e Superior, correlacionando-os com a Formação Araí de Pinheiro et al. (1990). Reis \& Carvalho (1996) e Reis \& Fraga (1999) concordaram com a subdivisão de Borges \& D'Antona (1988), mas não admitiram a correlação direta com a Formação Araí na seção-tipo. Definiram como Formação Tepequém a sucessão sedimentar isolada da serra homônima, estimada a espessura de 210 $\mathrm{m}$ para o pacote sedimentar. Tal sucessão foi interpretada por Borges \& D'Antona (1988) como depósitos de leques aluviais, eólicos e fluviais intercalados com fácies lacustre. Fernandes Filho \& Nogueira (2003), Fernandes Filho et al. (2008) e Truckenbrodt et al. (2008) descreveram, além de depósitos fluviais, fácies costeiras com estruturas de maré e onda, demonstrando que os depósitos da serra são oriundos de uma bacia mais ampla. Além disso, correlacionaram-nos com aqueles do BP, incluindo-os como formações dentro do Grupo Araí.

\section{DEPÓSITOS SILICICLÁSTICOS DA SERRA DO TEPEQUÉM A sucessão siliciclástica pa-} leoproterozoica da Serra do Tepequém constitui dois megaciclos granodecrescentes ascendentes de depósitos fluviais e costeiros, representados por arenitos, conglomerados, pelitos e ritmitos arenito/pelito, incluídos nos Grupos Araí e Suapi (Fig. 3). A 


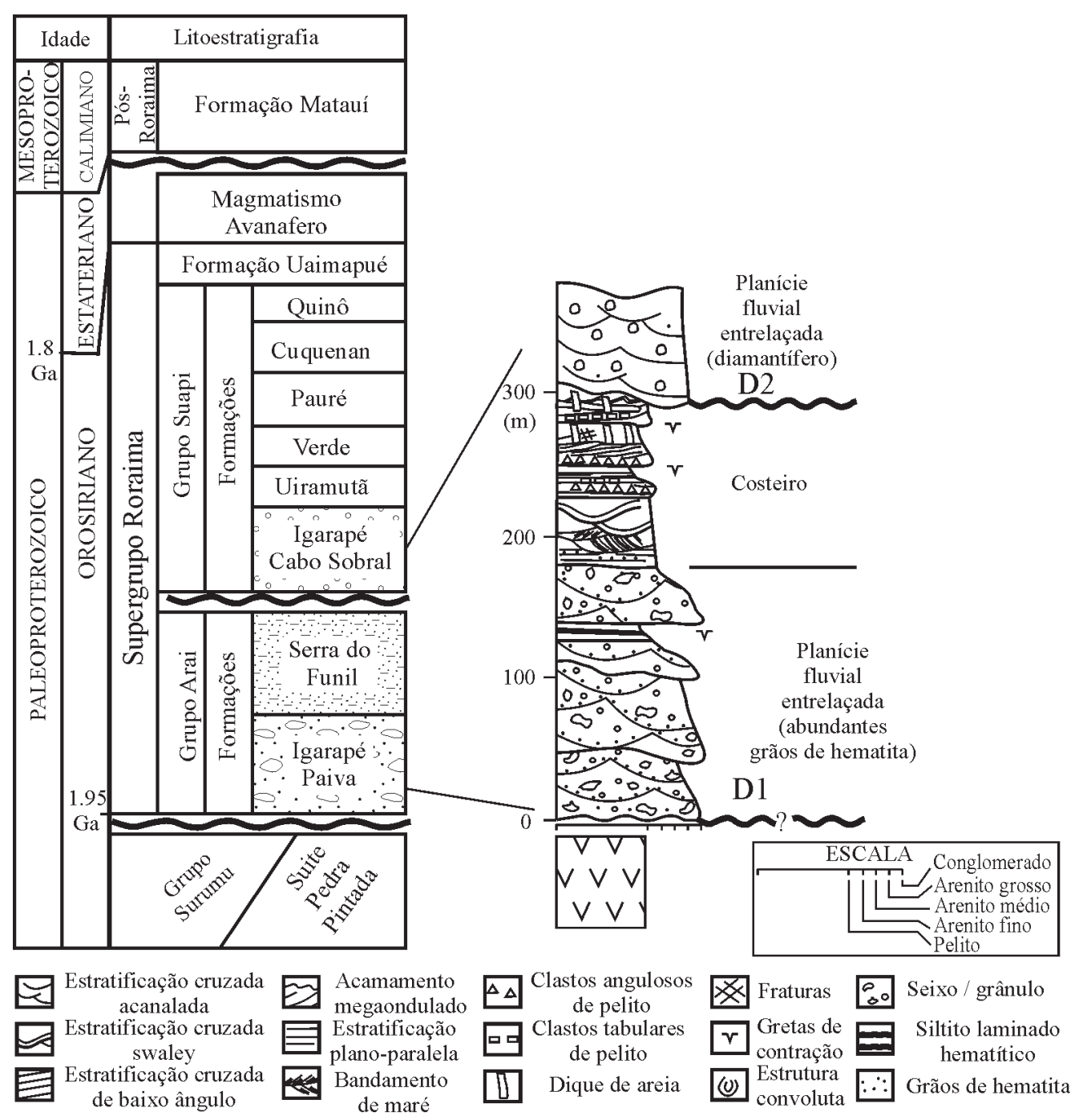

Figura 3 - Coluna estratigráfica do Supergrupo Roraima na Serra do Tepequém (modificada de Santos et al. 2003).

distribuição dessas unidades na serra é mostrada no mapa geológico da Fig. 4.

O primeiro megaciclo compõe o Grupo Araí, com depósitos fluviais proximais da Formação Igarapé Paiva na base, assentados sobre superfície erosiva (D1). São constituídos de conglomerados polimíticos, arenitos grossos a médios, com abundante estratificação cruzada acanalada e pelitos subordinados marcando o topo de cada ciclo. Tais rochas estão expostas na cachoeira do Funil, no desvio do igarapé Cabo Sobral - chamado "tilin" -, nas regiões E e SE da serra, bem como a montante do igarapé Paiva (Figs. 3 e 4 ).

Em contato gradual, sobrepõem-se depósitos fluviais influenciados por maré e onda, depósitos de planície e canal de maré, pertencentes à Formação Serra do Funil, e constituídos de arenitos finos a médios, pelitos e ritmitos arenito/pelito. Estratificação cruzada acanalada com pelitos nos limites dos sets, estratificação cruzada de baixo ângulo, estratificação cruzada swaley, acamamento flaser, wavy, linsen e bandamento de maré foram as estruturas sedimentares encontradas. Esses depósitos estão bem expostos em cortes de estrada nas encostas dos morros próximos à Cachoeira do Funil e nas voçorocas no interior da serra (Figs. 3 e 4).

O segundo megaciclo compreende depósitos fluviais do topo da sucessão da Serra do Tepequém, os quais estão incluídos na Formação Igarapé Cabo Sobral, que é a base do Grupo Suapi, e constituídos de arenitos seixosos a grossos e conglomerados oligomíticos. Estes depósitos estão bem representados no topo dos morrotes da serra, a exemplo do Morro da Antena. O limite estratigráfico entre ambos os grupos é discordante, marcado por superfície erosiva (D2) entre os depósitos costeiros da Formação Serra do Funil e os fluviais da Formação Igarapé Cabo Sobral (Figs. 3 e 4). 


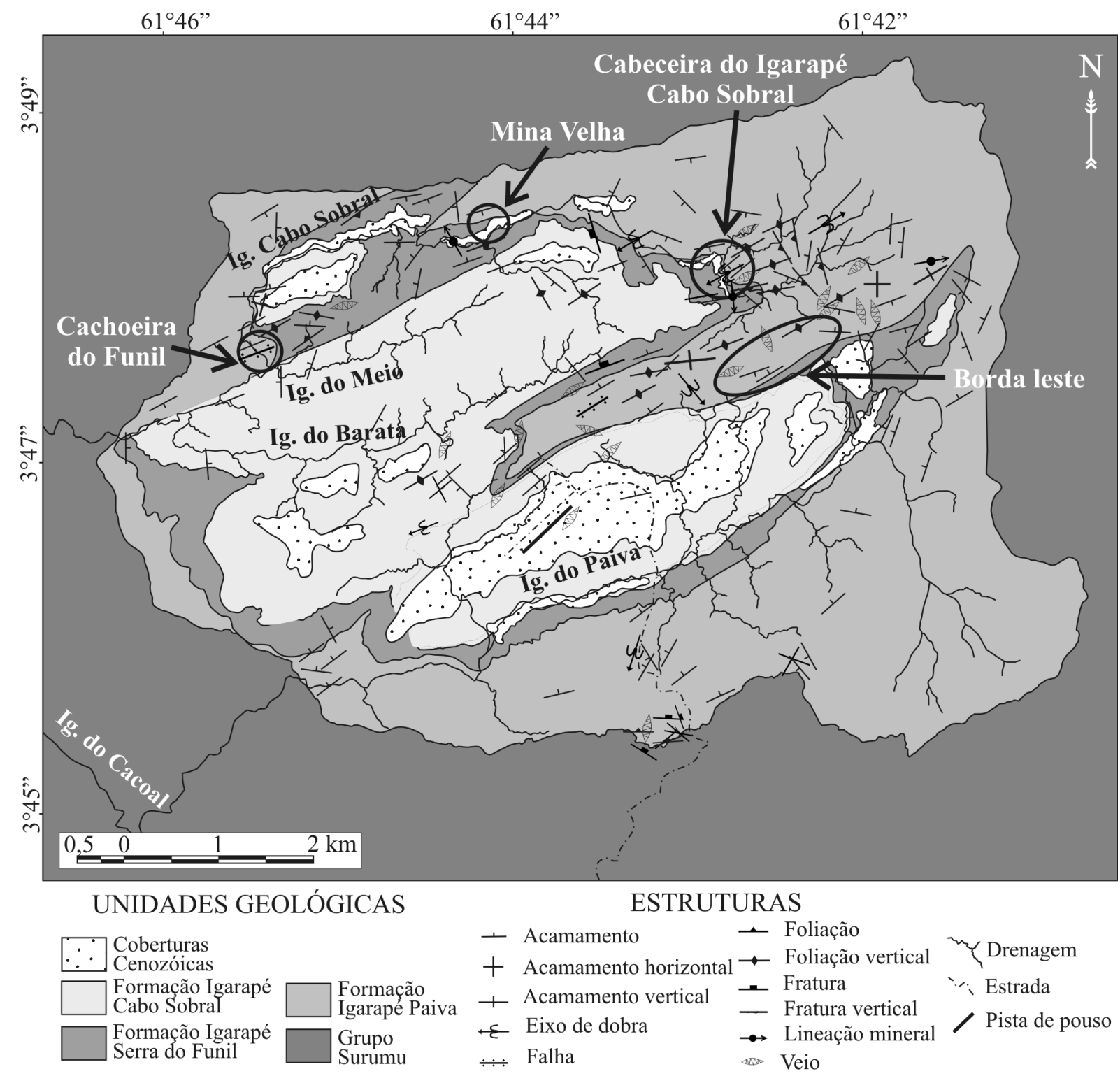

Figura 4-Mapa geológico da Serra do Tepequém e localização dos perfis estudados (setas).

ANÁLISE DAS ESTRUTURAS EM PRODUTOS DE SENSORES REMOTOS A Serra do Tepequém desenha, em imagens de sensores, uma forma aproximadamente romboédrica arredondada, com bordas fortemente orientadas nas direções ENEWSW e, secundariamente, NNW-SSW (Fig. 5).

Em escala regional, a área onde está inserida a serra apresenta lineamentos com direções NESW, NW-SE e, secundariamente, E-W, N-S e NNWSSE. Essas estruturas estão impressas nas rochas vulcânicas do Grupo Surumu, nos granitos da Suíte Intrusiva Pedra Pintada, nas rochas sedimentares do Supergrupo Roraima e nos granitos da Suíte Intrusiva Saracura (Fig. 2).

Os lineamentos na direção NW-SE, observados predominantemente na porção Oeste da área, formam um feixe, que se prolonga ao Sul, e controlam as bordas Sudoeste e Oeste das serras do Tepequém e Aricamã, junto aos lineamentos de direção E-W (Figs. 2 e 5). Nas bordas Sudeste e Leste da Serra do Tepequém, nota-se a ocorrência mais pronunciada dos lineamentos de direção NE-SW e N-S. Em relação à borda ao Norte, em padrão serrilhado, observa-se a influência dos lineamentos NW-SE e NE-SW (Fig. 5). Ao Norte da Serra do Tepequém sobre o embasamento, observa-se uma faixa de lineamentos de direção NE-SW, não observada na região Sul, que se projeta sobre os domínios das rochas sedimentares (Figs. 2 e 5). Em tais rochas predominam lineamentos NE-SW, que controlam morrotes com cotas altimétricas relativamente mais baixas e alinham as drenagens com cachoeiras. 

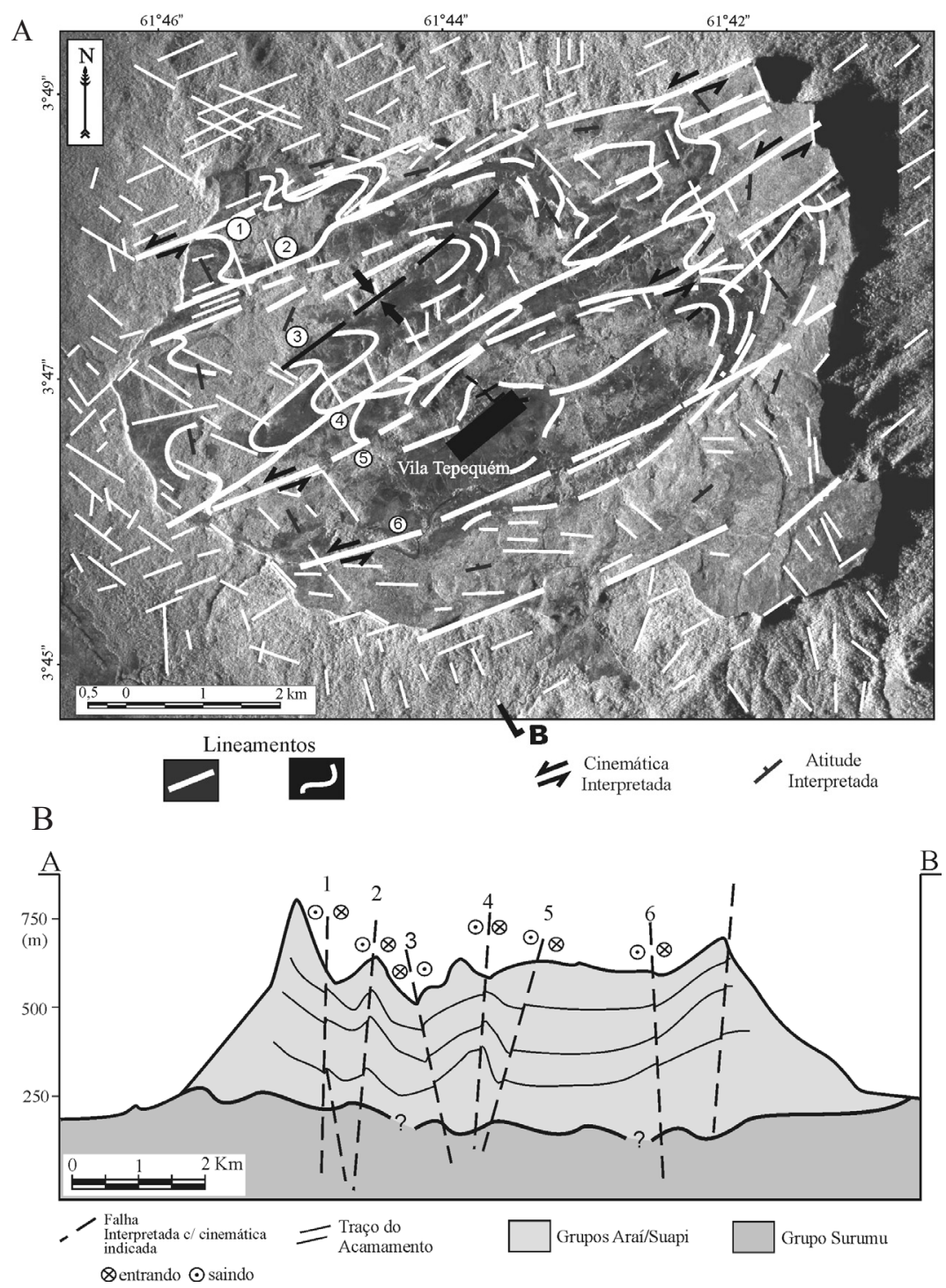

Figura 5 - (A) Lineamentos fotogeológicos da Serra do Tepequém e entorno, interpretados a partir da imagem de radar tipo radar de abertura sintética (SAR). Notar lineamentos nas direções NE, NW e, subordinadamente, EW e NS, bem como os curvos, indicativos de dobras. Os lineamentos principais seccionam a serra na direção NE com espaçamentos em torno de $2 \mathrm{~km}$ e foram interpretados como falhas direcionais sinistrais. (B) Seção geológica esquemática $A-B$, indicando a posição das falhas responsáveis pelo basculamento das camadas, desenhando dobras tipo kink bands e em chevron. Os números indicados correspondem às falhas mostradas na seção.

Os lineamentos NE-SW, projetados sobre o embasamento, dividem a Serra do Tepequém em setores, sendo o principal aquele associado ao bloco que soergue as bordas Leste e Sudeste da serra, com altitudes de até $1.100 \mathrm{~m}$, expondo conglomerados fluviais e arenitos. Os lineamentos que se prolongam em direção à borda Sudoeste separam os setores do Paiva e do Cabo Sobral (Figs. 2 e 5). Os lineamentos de direção NW-SE são observados em toda a serra, sendo mais comuns nos extremos Oeste, Nordeste e Sudeste, enquanto aqueles de direção E-W estão melhor registrados no extremo Sul (Fig. 5). Um trend secundário de lineamentos de direção NW-SE pode ser observado na porção Oeste da serra, truncando os lineamentos principais NE-SW.

A serra, ao ser vista nas imagens de sensores, notadamente de radar (Fig. 5), tem a particularidade de mostrar padrões de lineamentos curvos interpretados como sinformes e antiformes quilométricos, cortados pelas descontinuidades NE-SW, com fortes indicativos de componente cinemático direcional sinistral. A interpretação desta cinemática é corroborada pela falta de continuidade lateral e supressão das unidades geológicas no mapa (Fig. 4).

$\mathrm{Na}$ imagem interpretada (Fig. 5), observa-se um conjunto de três dobras quilométricas com eixos 
de direção NE-SW e caimento para SW, desenhando-se em mapa um " $\mathrm{M}$ " suavemente assimétrico, composto por dois sinformes e um antiforme central, este transposto por lineamentos NE-SW anastomóticos. As dobras interpretadas ocupam restritamente o espaço cartográfico da serra, não sendo observadas nas áreas arrasadas adjacentes, correspondentes às rochas do embasamento.

Os lineamentos, NE-SW, associados às dobras, ao contrário, transpõem os limites da serra, sendo, portanto, comuns aos dois terrenos distintos: embasamento, com topografia baixa e plana, e cobertura sedimentar no domínio da serra. A seção esquemática da Fig. 5B representa a presença das dobras e sua possível relação com as rochas do embasamento.

\section{ESTRUTURAS}

TECTÔNICAS

EM

AFLORAMENTOS As principais estruturas tectônicas impressas nas rochas da Serra do Tepequém são falhas, fraturas, veios, dobras, foliação e lineação.

As zonas de falhas, de maior escala, seccionam a serra na direção NE-SW. Essas zonas mostram continuidade no embasamento (Fig. 5), como foi discutido com relação aos lineamentos nos sensores.

Em campo, as rochas apresentam camadas com mergulhos variáveis, fraturadas, com indicação de deslocamentos entre blocos, dobras forçadas e de arrasto, veios em fraturas de tensão e em padrões en echelon em tension gashes. É possível ainda observar, localmente, uma discreta foliação anastomótica com lineação construtiva subordinada.

Indicadores cinemáticos de trama são raramente encontrados, provavelmente devido à granulometria relativamente grossa das rochas, restringindo-se à rotação dos planos de acamamento, à assimetria de veios e na presença das dobras de arrasto.

$\mathrm{O}$ acamamento, na maioria das vezes, não é facilmente discernível no campo, em função da presença de depósitos siliclásticos grossos com estratificação cruzada acanalada, nos quais os limites de sets representam superfícies erosivas, não horizontais e não deposicionais na sua origem. Por sua vez, camadas de pelito, ideais para este propósito, ocorrem apenas localmente nas fácies fluviais, sendo mais frequentes nos depósitos costeiros.

Zonas de falhas Formam faixas com largura variando de dois a dezenas de metros, sendo contínuas por quilômetros e caracterizadas pela presença de foliação cataclástica espaçada milimétrica à submilimétrica, anastomótica, com veios de quartzo leitoso, apresentando predominantes mergulhos altos a subverticais (Figs. 6 a 10).

As zonas de fraturas ocorrem com direção predominante NE-SW e secundariamente NW-SE. As fraturas nos arenitos apresentam praticamente todas as direções (Fig. 9C). Quando ocorrem em baixa frequência, possuem direções principais NE-SW e NNW-SSE e secundárias, WNW-ESE, todas geralmente apresentando mergulhos altos a subverticais (Fig. 9C). Na maioria das vezes, ocorrem em feixes e pares conjugados de fraturas, fazendo entre si ângulos aproximadamente retos.

A foliação do tipo cataclástica é levemente sinuosa, penetrativa, com espaçamento milimétrico a centimétrico. É mais bem desenvolvida nas rochas de granulometria mais fina, como pelitos e arenitos finos, mas também está presente em arenitos grossos com seixos e conglomerados, e é localmente marcada pela imbricação planar de seixos estirados. A atitude predominante dessa foliação é ENE, com mergulhos acima de $80^{\circ}$; contudo, direções E-W e planos com mergulhos menores são também encontrados (Fig. 6C). Embora a foliação seja relativamente forte nas rochas investigadas, não é penetrativa em todas, tornando-se mais comum próxima às zonas de falhas, nas quais concentra-se em faixas relativamente longas (com dezenas de quilômetros) e com largura de dezenas até poucas centenas de metros (Fig. 6A). É bem mais expressiva na região central da serra, em que as imagens de sensores indicam a maior intensidade de partição das dobras (Figs. 5A e 6A).

Os veios de quartzo, com posição oblíqua em relação às bordas das zonas de falhas, apresentam espessuras variando de milímetros a poucas dezenas de centímetros, com comprimentos métricos. Ocorrem desde vênulas até veios de grande porte, subparalelos entre si, retos ou sinuosos (Fig. 7). Tais veios, em planta, mostram-se subparalelos às zonas de falhas, mas, em perfil, apresentam mergulhos de $50^{\circ}$ a $70^{\circ}$ (Fig. 7A).

Além dos veios tabulares (Fig. 7C), ocorrem ainda famílias de veios descontínuos en echelon, com assinatura em "Z", indicativa de componente cinemático dextral associado às zonas de falhas normais. Em planta, os pares conjugados de veios en echelon exibem assinaturas em "Z" e "S" (Fig. 7B).

Nas seções investigadas ao longo do Igarapé Cabo Sobral, na Cachoeira do Funil (Fig. 9A) e a montante do igarapé (Fig. 8), observou-se o efeito 

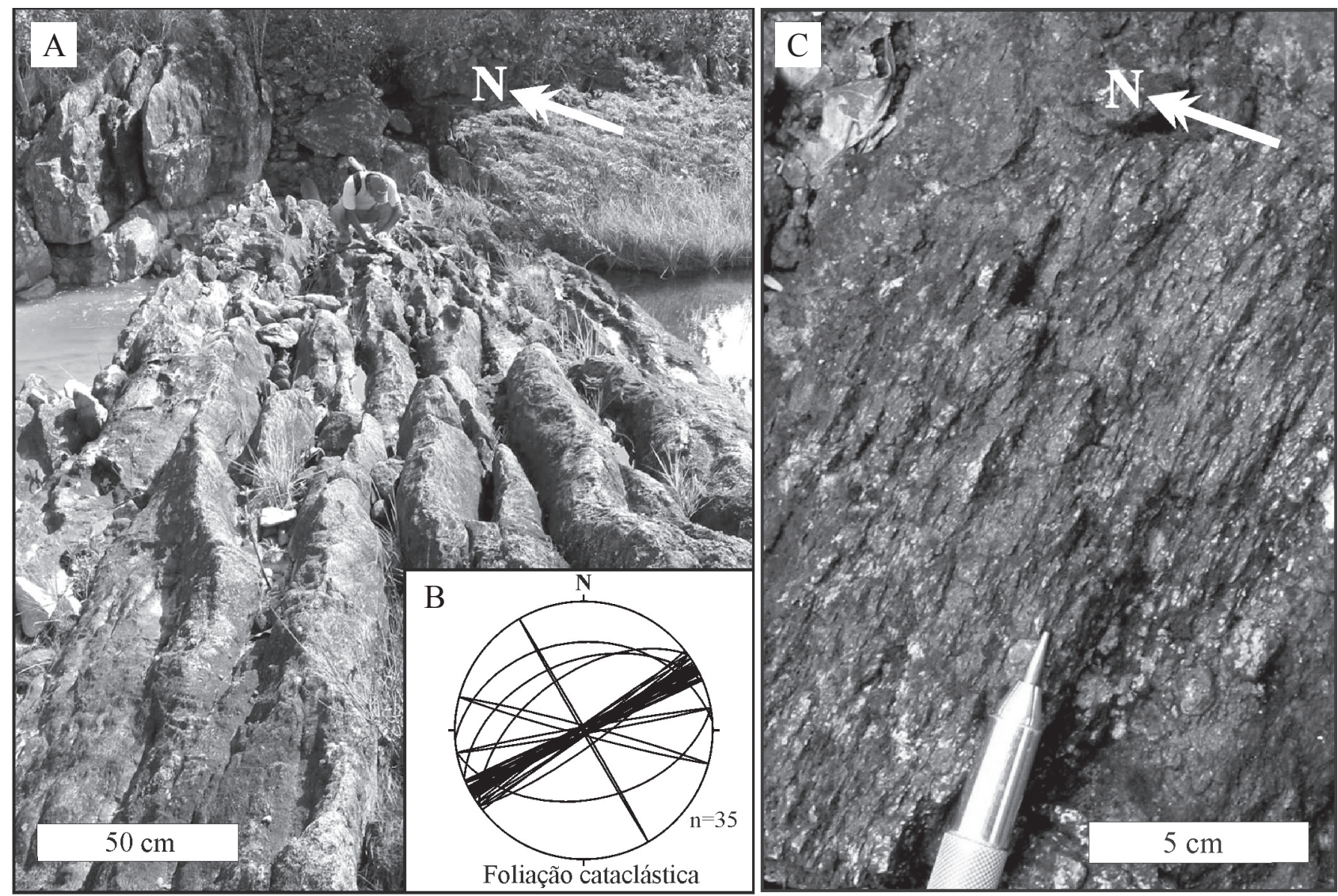

Figura 6- (A) Aspecto da foliação cataclástica desenvolvida em arenitos da fácies fluvial, realçada por sulcos decorrentes da dissolução e da erosão, região da Mina Velha; (B) estereograma para planos de foliação cataclástica mostrando direção preferencial ENE-SWW com fraco espalhamento decorrente das variações do mergulho e $(C)$ detalhe da foliação cataclástica em arenitos.
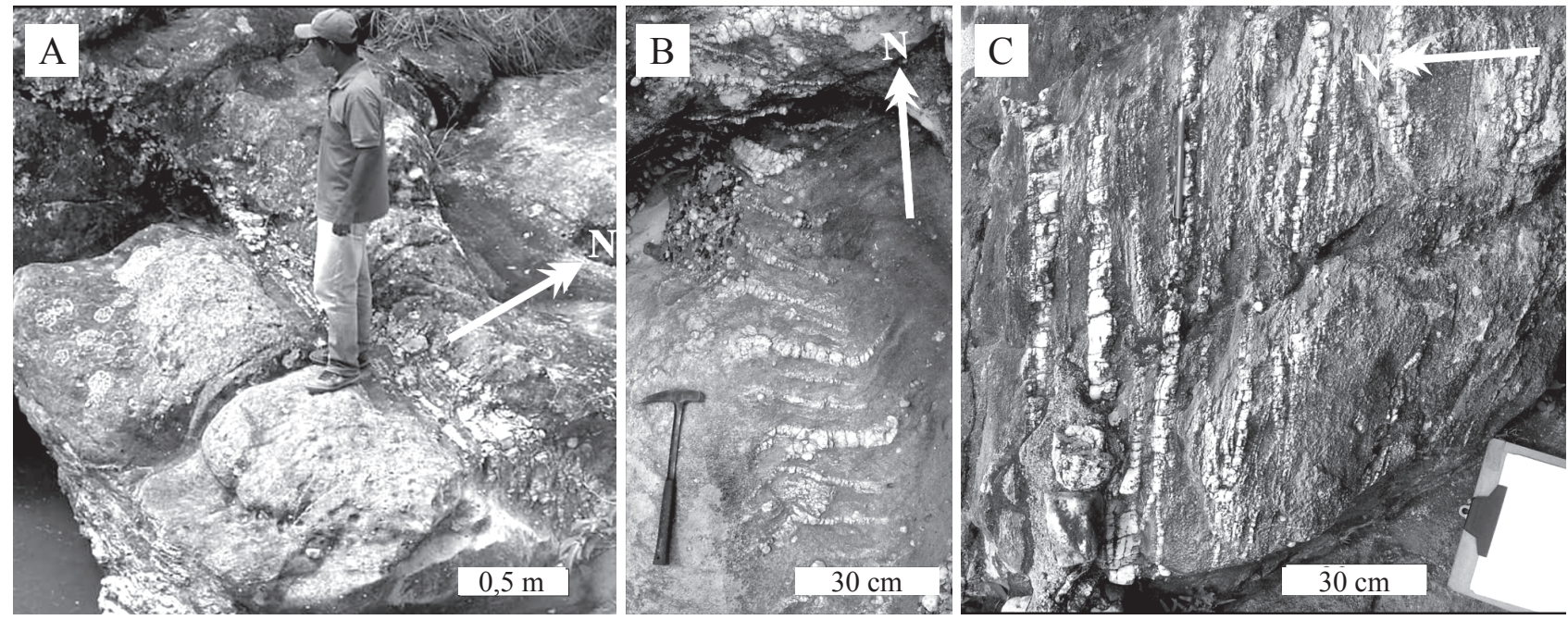

Figura 7 - Padrões de veios de quartzo leitoso observados na área a montante do igarapé Cabo Sobral (veja mapa na Fig. 4). (A) Veios tabulares centimétricos em arranjos intraestratais; (B) arranjos de veios en echelon em tension gash com indicação de cinemática sinistral; (C) veios subverticais, acompanhando conjuntos de fraturas T que truncam as camadas de arenitos.

das zonas de falha sobre o acamamento, marcado pela presença de conjuntos de falhas normais com atitudes em torno de NE-SW e mergulhos variáveis de 20 a $70^{\circ}$ para NW.

Na seção da Cachoeira do Funil (Fig. 9A), as falhas normais, espaçadas entre 30 a $50 \mathrm{~m}$, ocasionam rotações anti-horárias e horárias no acamamento, gerando dobras em chevron de até poucas centenas de metros. Em geral, o acamamento tem direção ENESSW, mas seu mergulho, em consequência das falhas, mostra ângulos de 35 a $63^{\circ}$ ora para NNW ora para ESE. 


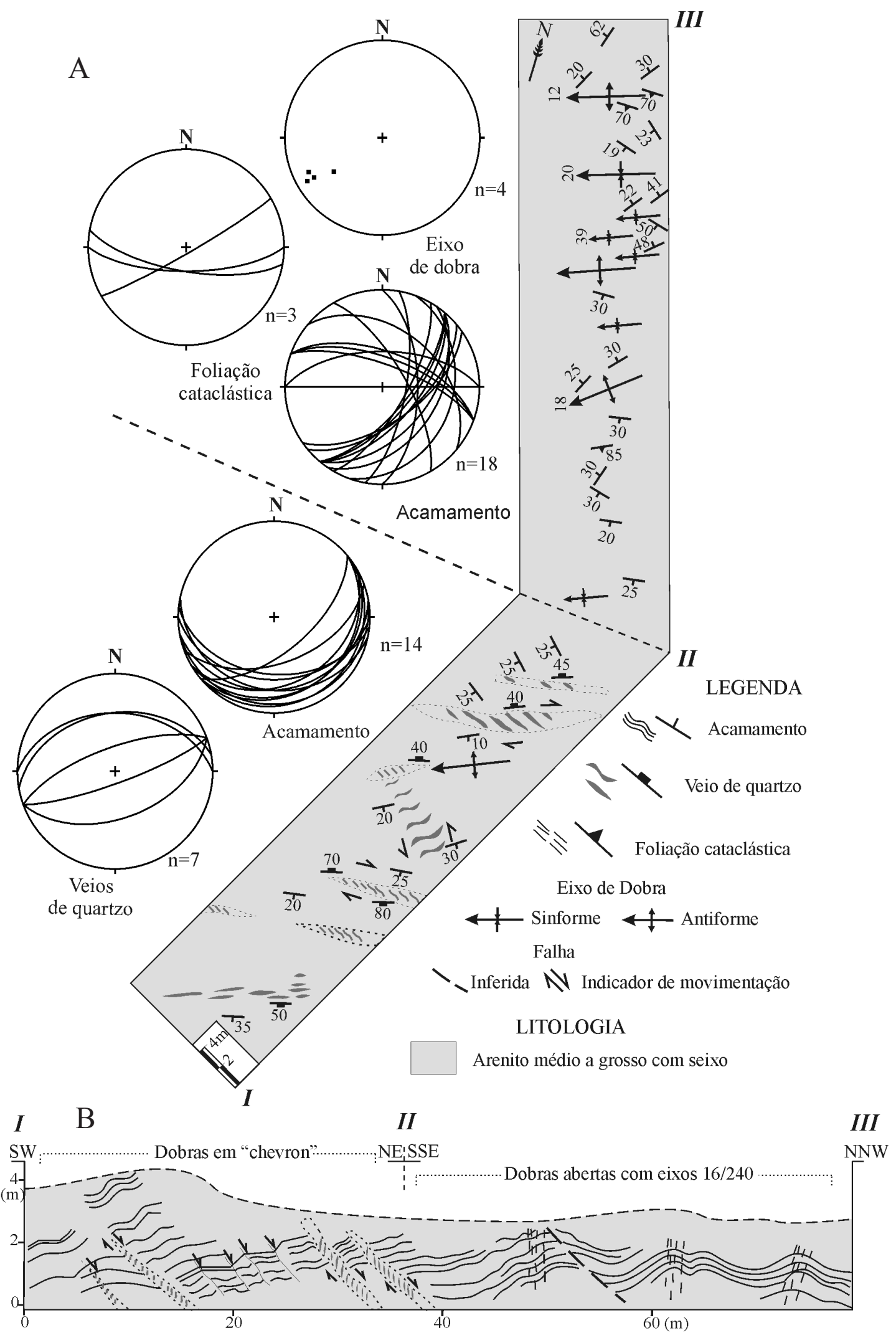

Figura 8 - Distribuição de dobras e falhas perfil a montante do igarapé Cabo Sobral, Nordeste da Serra do Tepequém (Fig. 3). (A) Em mapa e (B) em perfil. Na porção NNW do perfil, o acamamento desenha dobras seccionadas por zonas de foliação cataclástica em posição plano axial. Na parte $S W$ do perfil, predominam falhas normais, que deslocam o acamamento desenhando dobras em chevron. Na porção Norte do mapa, o acamamento desenha dobras com eixos em posição aproximadamente E-W. Ao Sul, são observados pares conjugados de zonas de cisalhamento com cinemática sinistral e dextral subparalelas ao eixo de dobra. Ambas as zonas estão associadas a veios de quartzo leitoso com arranjos en echelon. 
A

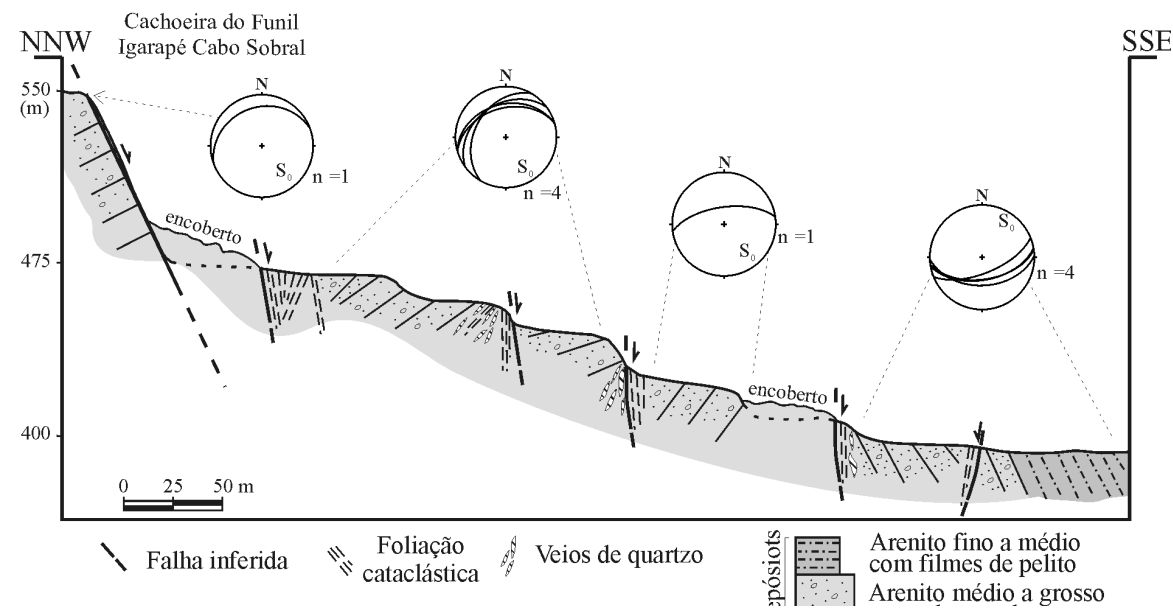

B

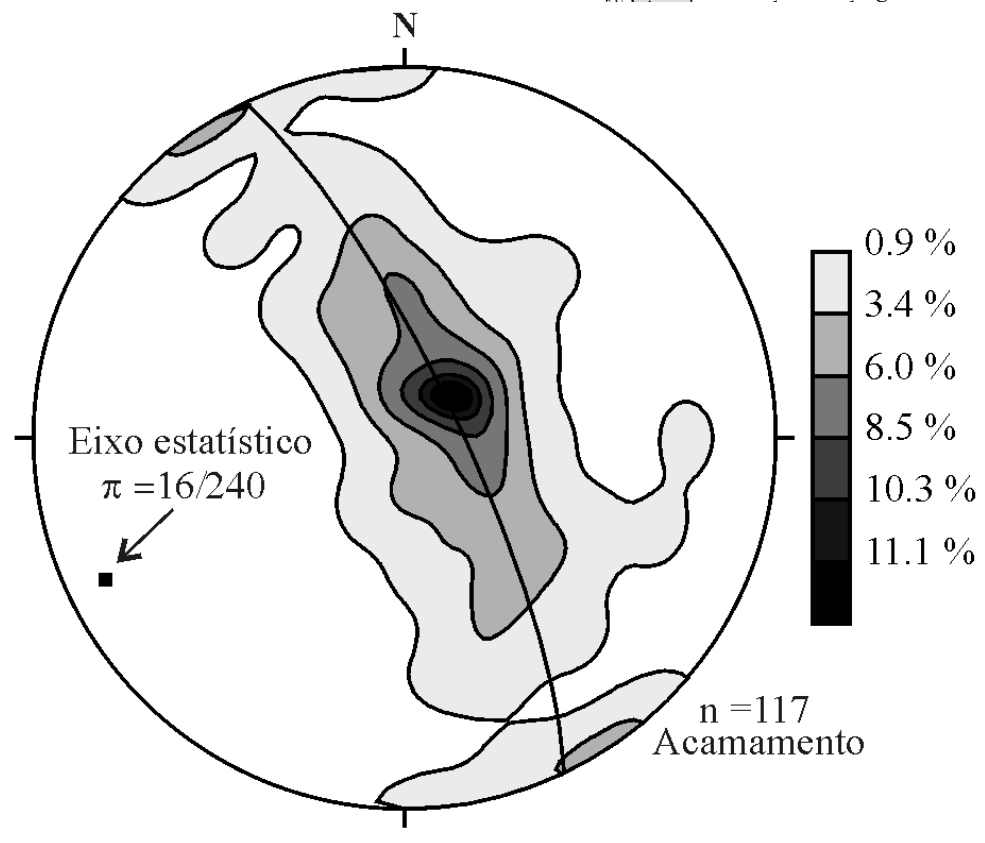

$\mathrm{C}$

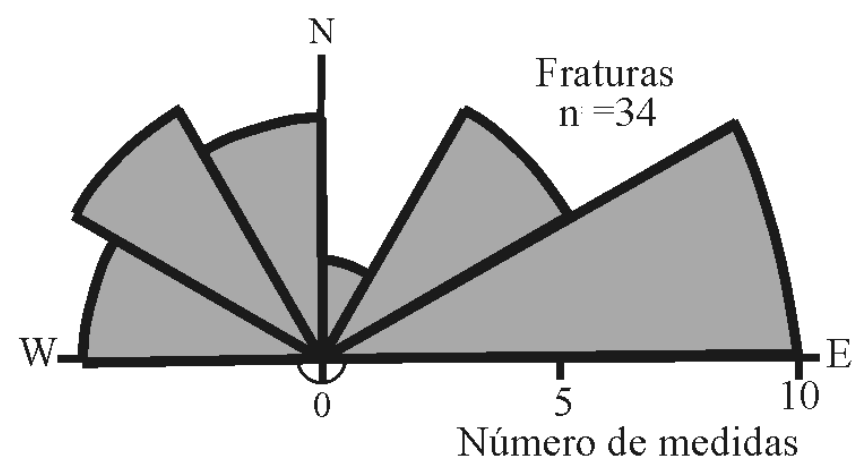

Figura 9 - (A) Seção geológica na Cachoeira do Funil, Noroeste da Serra do Tepequém. O acamamento exibe variações no mergulho em diferentes blocos separados por falhas normais, geralmente associadas com veios de quartzo leitoso. (B) Diagrama estereográfico de contorno (máxima de concentração $>11 \%$ ) para o acamamento, desenhando guirlanda indicando eixo $\pi$ em torno de $16^{\circ} / 240^{\circ} \mathrm{Az}$. (C) Diagrama de roseta para fraturas, mostrando orientações preferencialmente para SSW e NE.

A montante do Igarapé Cabo Sobral (Fig. 8), na região Nordeste da serra, é possível observar o efeito das falhas normais sobre o acamamento de arenitos com a formação de dobras e veios. $\mathrm{O}$ acamamento nos arenitos grossos tem direção variando entre NE-SW, E-W e NW-SE e mergulho entre 10 a $50^{\circ}$, é deslocado por falhas normais com direção em torno de ENEWSW e mergulhos de 40 a $80^{\circ}$ para NNW e SSW. O 

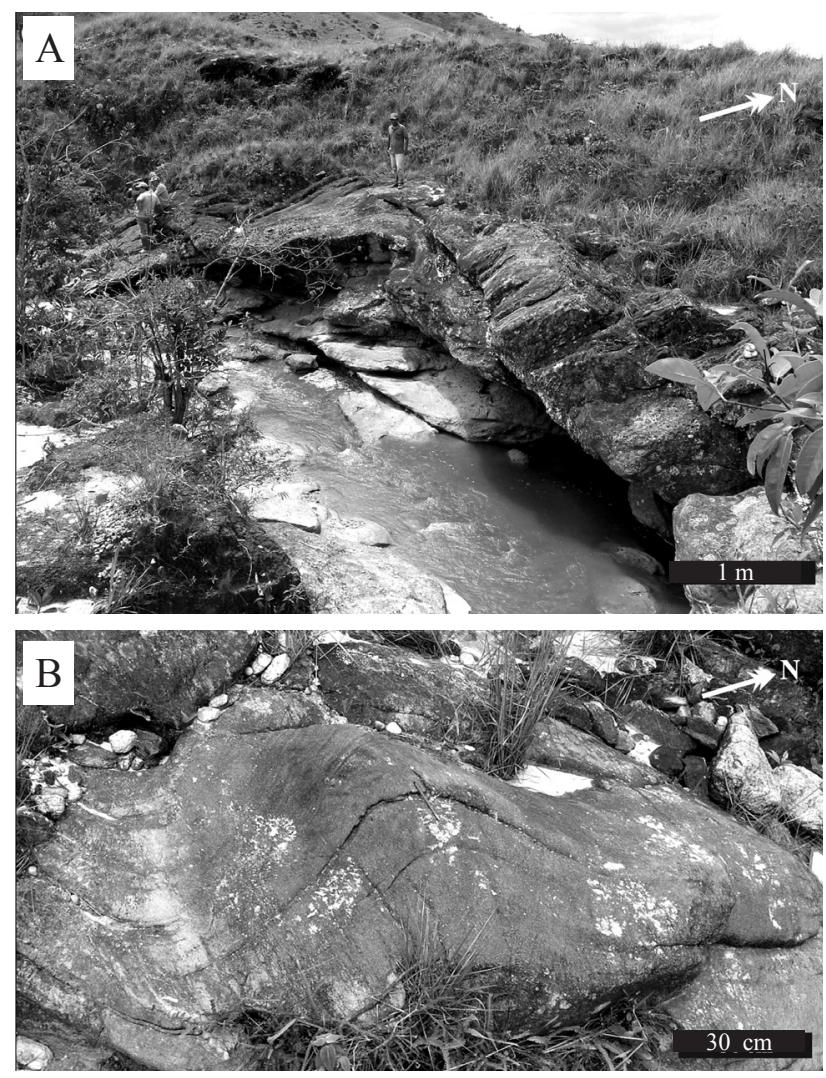

Figura 10-Dobras em arenitos da Formação Igarapé Cabo Sobral, na região do igarapé homônimo. (A) Antiforma assimétrica, associada com veios de quartzo intraestratal. (B) Antiforma e sinforma paralelas simétricas, apresentando foliação plano axial vertical.

efeito dessas falhas sobre o acamamento produz dobras em chevron e flexurais abertas a suaves, com foliação cataclástica discreta em posição plano axial N30E/85NE, ocorrem tension gashes associados.

Os polos de 117 medidas de acamamento, plotados em diagrama de contorno, mostram guirlanda indicativa da presença de dobras (Fig. 9B).

$\mathrm{O}$ acamamento mostra-se deformado por rotação próximo às zonas de falha NE-SW, nas quais se apresenta com ângulos altos de mergulho ou até mesmo na posição vertical, a exemplo da região da cachoeira do Funil (Fig. 9A). O acamamento pode ainda desenhar dobras de arrasto e em kink bands, como a montante do igarapé Cabo Sobral (Fig. 8).

Dobras As dobras presentes são do tipo chevron e kink band e, raramente, flexural. Têm dimensões decimétricas a quilométricas e são abertas e paralelas. As dobras maiores, quilométricas, já discutidas, foram interpretadas a partir das imagens de sensores.

As dobras, de escala decimétrica à métrica, são assimétricas, suaves a abertas e aproximadamente paralelas, segundo a classificação de Ramsay (Ramsay \& Huber 1983, 1987). Os eixos possuem caimentos de 12 a $39^{\circ}$ para WSW, com atitude média de $16^{\circ} / 240^{\circ} \mathrm{Az}$. Na região a montante do igarapé Cabo Sobral, os planos axiais das dobras são marcados pela foliação cataclástica, anteriormente mencionada, que se apresenta com mergulhos altos para NNW, indicativa de vergência para SSE (Fig. 10B). Dobras de escala decimétrica deformam sets de estratificação cruzada acanalada (Fig. 10B).

A posição dos planos de acamamento, a partir do diagrama de contorno de polos (Fig. 9B), desenha uma guirlanda representativa de dobra cilíndrica, com atitude estatística de 16/240. No devido estereograma, chama atenção a presença de duas regiões de contornos máximos relativos indicativos da presença de camadas subverticais com direção aproximada de NE-SW (em cerca de 55 a $60^{\circ}$ Az), participando do desenho dessas dobras ou pelo menos interferindo nas mesmas. Esse conjunto de camadas subverticais é observado particularmente na Cachoeira do Funil (Fig. 9B) e está nitidamente relacionado às zonas de falhas em que o acamamento exibe rotação máxima.

\section{DISCUSSÕES E CONCLUSÕES A análise es-} trutural das rochas da Serra do Tepequém revelou um arranjo de camadas com mergulhos variáveis para SE e $\mathrm{NW}$, disposto em domínios de direção NE-SW (N65 E), os quais estão limitados por falhas oblíquas com rejeitos normais e inversos. Como exemplo, as rochas no perfil da Cachoeira do Funil mostram essa organização, na qual blocos balizados por planos de falhas exibem inclinações tanto para NW quanto SE, com mergulhos variando de 5 a $30^{\circ}$. Próximo aos planos de falhas, o acamamento é geralmente subvertical. Assim, a estrutura da Serra do Tepequém é interpretada em um arranjo camada/falha, gerando dobras em chevron e kink bands, as quais têm reflexo principalmente no padrão observado em escala quilométrica, bem visualizado nos produtos de sensores remotos, mas também verificado na escala de afloramento (Fig. 5A).

A deformação das rochas na serra está distribuída em diferentes domínios, cujos limites são as falhas oblíquas NE-SW que acompanham as direções das estruturas planares regionais, tal como observa-se nos diferentes sensores utilizados. Trata-se de deformação produzida em regime rúptil a rúptil-dúctil, afetando camadas com diferentes competências e características mecânicas a esse estilo de deformação.

Em cada domínio estrutural, as diferentes condições de strain desenham situações geométricas próprias. As fraturas são capazes de produzir dobras de arrasto, 
nas quais predominam condições mecânicas mais plásticas, em contraste com domínios de deformação rúptil, nos quais as dobras desenham chevrons e kink bands.

A história tectônica regional pode ser sumariamente descrita como relacionada, inicialmente, à presença de forte trama dúctil nas rochas do embasamento adjacente, vulcânicas do Grupo Surumú, granitos das suítes Pedra Pintada e Saracura e às rochas associadas ao Cinturão Cauarane-Coereni, no qual importantes bandas e zonas de cisalhamento desenham o quadro dúctil da estruturação regional.

Reativações de natureza rúptil a rúptil-dúctil dessas estruturas antigas do embasamento se projetaram tardiamente sobre as rochas da cobertura, durante o Episódio K'Mudku ( 1,2 Ga), e desenharam sobre esses pacotes os conjuntos de dobras forçadas e de arrasto observadas nos níveis de erosão atuais (Figs. 5, 8, 9Ae 10). O controle reológico impôs predominantemente duas diferentes tramas, com a formação de foliação do tipo cataclástica (clivagem de fratura) e de fraturas em feixes discretos sobre rochas, refletindo suas distintas suscetibilidades mecânicas e distribuição de strain (Figs. 6 e 7).

Portanto, o arcabouço geométrico observado é característico de um ambiente de deformação de nível crustal raso a médio, e a história tectônica é controlada por reativações dos planos de fraqueza preexistentes nas tramas antigas, dúcteis, do embasamento. Assim sendo, a sucessão de rochas siliciclásticas, que atualmente compõem a Serra do Tepequém, pertencentes aos grupos Araí e Suapi, base do Supergrupo Roraima, constitui parte preservada de uma ampla bacia seccionada por soerguimentos e erosão, em discordância sobre o embasamento.

AGRADECIMENTOS Este artigo apresenta parte dos resultados da Tese de Doutorado de Lucindo A. Fernandes Filho, desenvolvida no Programa de Pósgraduação em Geologia e Geoquímica da Universidade Federal do Pará (UFPA). Os agradecimentos são extensivos à Universidade do Federal do Amazonas (UFAM) e ao Serviço Geológico do Brasil (CPRM), pelo apoio logístico, à Coordenação de Aperfeiçoamento de Pessoal de Nível Superior (Capes), pela concessão de bolsa a L.A.F.F., ao Conselho Nacional de Desenvolvimento Científico e Tecnológico (CNPq), pelo apoio financeiro aos trabalhos de campo, concedido a W.T. (processo 473483/2004-1) e pela bolsa de produtividade em pesquisa à A.C.R.N. Agradecemos também aos geólogos José Bandeira Cavalcante da Silva Júnior e Paulo José Mota da Silva, pela contribuição nas etapas de campo e confecção das figuras.

\section{Referências}

Almeida F.F.M., de Hasui Y. 1984. Introdução. In: Almeida F.F.M. \& de Hasui Y. (eds.) O Pré-Cambriano do Brasil. São Paulo, Edgar Blücher, 378 p.

Barron C.N. 1966. Notes on the stratigraphy of Central British Guiana. In: DNPM, Conf. Geol. Interg., 6, Belém, Anais, p.121-126. Avulso n. 41.

Berrangé J.P. 1977. The geology of southern Guyana, South America. Overseas. Memoir 4, Institute of Geological Sciences, London, p.12.

Borges F.R. \& D’Antona R. de J.G. 1988. Geologia e mineralizações da serra Tepequém. In: SBG, Cong. Bras. Geol., 35, Belém, Anais, 1, p.155-163.

Bouman Q.C. 1959. The Roraima Formation, northern part of Territorio do Rio Branco. Rio de Janeiro, Petrobrás/ Renor, Relatório Técnico 350-A, p.17.

Braun O.P.G. 1973. Projeto Roraima, 2 a Fase; Levantamento geológico integrado: Relatório de mapeamento preliminar ao milionésimo, correspondente à "Fotointerpretação preliminar". Manaus, DNPM/CPRM, 218 p. il.

Costa J.B.S., Pinheiro R.V.L., Reis N.J., Pessoa M.R., Pinheiro S. da S. 1991. O hemigraben do Tacutu, uma estrutura controlada pela geometria do Cinturão de Cisalhamento Guiana Central. Geociências, 10:119-130.

Fernandes Filho L.A. \& Nogueira A.C.R. 2003. Fácies de um Sistema Fluvial-Litorâneo Proterozoico na Serra do Tepequém, estado de Roraima. In: SBG, Simp. Geol. Amaz., 8, Manaus, CD-Rom.

Fernandes Filho L.A. 1990. Estratigrafia da Serra do Tepequém. In: SBG, Cong. Bras. Geol. 36, Natal, Anais, 1, p. 199-210.

Fernandes Filho L.A., Truckenbrodt W., Nogueira A.C.R. 2008. Fácies e estratigrafia da sucessão sedimentar Paleoproterozoica da Serra do Tepequém, sul do Escudo das Guianas. In: SBG, Cong. Bras. Geol., 44, Curitiba. Anais, CD-Rom.

Fraga L.M.B. 1999. Geologia Estrutural. In: Programa de Levantamento Geológicos Básicos do Brasil. Roraima Central, Folhas NA.20-X-B e NA.20-X-D (inteiras), NA.20-X-A, NA.20-X-C, NA.21-V-A e NA.21-V-C (parciais). Escala 1:500.000. Estado do Amazonas, Brasília: CPRM, 1999. Relatório final, cap. 4, p. 117-128.

Fraga L.M.B. 2002. A Associação Anorrtosito-Mangerito Granito Rapakivi (AMG) do Cinturão Guiana Central e suas encaixantes paleoproterozoicas: Evolução estrutural, Geocronologia e Petrologia. Tese de Doutorado, Instituto de Geociências, Universidade Federal do Pará, 351 p.

Fraga L.M.B. 2010. Evolução tectônica. In: Fraga L.M.B., Dreher A.M., Grazziotin H., Reis N.J., Ragatky D. 
Geologia e Recursos Minerais da Folha Vila Tepequém - NA.20-X-A-III Estado de Roraima, escala 1:100.000. CPRM-SUREG-Manaus. (no prelo).

Fraga L.M.B., Grazziotin H., Dreher A.M., Farias M.S.G. 2010. Mapa Geológico. In: Fraga L.M.B., Dreher A.M., Grazziotin H., Reis N.J., Ragatky D. Geologia e Recursos Minerais da Folha Vila Tepequém - NA.20-X-A-III Estado de Roraima, escala 1:100.000. CPRM-SUREGManaus. (no prelo).

Fraga L.M.B., Macambira M.J.B., Dall'Agnol R., Costa J.B.S. 2009. 1,94-1,93 Ga charnockitic magmatism from the central parto f Guyana Sheild, Roraima, Brazil: Single-zircon evaporation data and tectonic implications. Journal of South American Earth Sciences, 27:247-257.

Fraga L.M.B., Reis N.J., Costa J.B.S. 1998. O Cinturão Guiana Central no Estado de Roraima. In: SBG, Cong. Bras. Geol., 40, Belo Horizonte, Anais, p. 411.

Fraga L.M.B., Reis N.J., Dall'Agnol R., Armstrong R. 2008. Cauarane-Coeroeni Belt - The tectonic southern limit of the preserved Rhyacian crustal domain in the Guyana Sheild, northern Amazonian craton. In: Int. Geol. Cong., 33, Oslo, Noruega. CD-Rom.

Fraga L.M.B., Reis N.J., Pinheiro S. da S. 1994a. Serra Tepequém: Uma estrutura relacionada à inversão da Bacia Roraima. In: SBG, Cong. Bras. Geol., 38, Camboriú, Resumo Expandido, p. 294-295.

Fraga L.M.B., Reis N.J., Pinheiro S. da S. 1994b. Arranjo estrutural do segmento sul do bloco Pacaraima, Estado de Roraima. In: SBG, Simp. Geol. Amaz., 4, Belém, Anais, p. 7-9.

Fraga L.M.B., Reis N.J., Riker S.R.L. 1999. Mapa Geológico. In: Programa de Levantamento Geológicos Básicos do Brasil. Roraima Central, Folhas NA.20-X-B e NA.20-X-D (inteiras), NA.20-X-A, NA.20-X-C, NA.21-V-A e NA.21$V$-C (parciais). Escala 1:500.000. Estado do Amazonas, Brasília, CPRM, 1999. Relatório final.

Gibbs A.K., Barron C.N. 1993. The Geology of the Guiana Shield. Oxford University Press, Oxford, 246 p.

Kroonenberg S.B. 1976. Amphibolite-facies and granulitefacies metamorphism in the Coeroeni-Lucie area, southwestern Surinam. Ph.D. Thesis, Amsterdan, Geologie em Mijnbouw, Dienst sur. Med., 25, p. 109-289.

Lima M.I.C., Oliveira E.P., Tassinari C.C.G. 1982. Cinturões granulíticos da porção setentrional do Cáton Amazônico. In: SBG, Simp. Geol. Amaz., 1, Belém, Anais, 1, p. 147162.

Montalvão R.M.G., Muniz M.B., Issler R.S., Dall'Agnol R., Lima M.I.C., Fernandes P.E.C.A., Silva G.G. 1975. Geologia da Folha NA.20 - Boa Vista e parte das Folhas NA.21 - Tumucumaque, NB.20 - Roraima e NB.21. In: Brasil. DNPM. Projeto RADAMBRASIL. Folha NA.20 - Boa Vista e parte das Folhas NA.21-Tumucumaque, NB.20 - Roraima e NB.21. Rio de Janeiro, 1975. (Levantamento de Recursos Minerais, 8).

Pinnheiro S.S., Reis N.J., Costi H.T. 1990. Geologia da Região de Caburaí - nordeste de Roraima. Relatório Final. Manaus, DNPM/CPRM, 1. il., 91 p.

Ramsay J.G. \& Huber M.I. 1983. The Techniques of Modern
Structural Geology: Strain Analysis. London, Oxford, Academic Press. 1. 307 p.

Ramsay J.G. \& Huber M.I. 1987. The Techniques of Modern Structural Geology: Folds and Fractures. London, Oxford, Academic Press. 2, 700 p.

Reid A.R. 1972. Stratigraphy of type area of the Roraima Group, Venezuela. In: Interg. Geol. Conf., 9, GeorgetownGuiana, p. 343-353, Boletim Especial 6.

Reis N.J. \& Carvalho A.S. 1996. Coberturas sedimentares do Mesoproterozoico do estado Roraima - Avaliação e discussão de seu modo de ocorrência. Revista Brasileira de Geociências, 26:217-226.

Reis N.J. \& Fraga L.M.B. 1999. Estratigrafia: Sinopse Estratigráfica. In: Fraga L.M.B. 1999. Programa de Levantamento Geológicos Básicos do Brasil. Roraima Central, Folhas NA.20-X-B e NA.20-X-D (inteiras), NA.20-X-A, NA.20-X-C, NA.21-V-A e NA.21-V-C (parciais). Escala 1:500.000. Estado do Amazonas, Brasília, CPRM, 1999. Relatório final, cap. 3.1, p. 15-17.

Reis N.J., Fraga L.M.B., Faria M.S.G. \& Almeida M.E. 2003. Geologia do Estado de Roraima, Brasil. In: Géologie de la France, vols. 2-4, p.121-134.

Santos J.O.S., Potter P.E., Reis N.J., Hartmann L.A., Fletcher I.R., McNaughton N.J. 2003. Age, source and Regional Stratigraphy of the Roraima Supergroup and Roraimalike Sequences in Northern South America, based on $\mathrm{U}-\mathrm{Pb}$ Geochronology. Geological Society of America Bulletin, 115:331-348.

Santos J.O.S., Hartman L.A., Gaudette H.E., Groves D.J., Mcaugthon N.J., Fletcher R. 2000. Anew understanding of the Provinces of the Amazon Craton based on ntergration of Field mapping and U-Pb and $\mathrm{Sm}-\mathrm{Nd}$ geocronology. Gondwana Research, 3:453-488.

Schobbenhaus C., Hoppe A., Lork A. Baumann A. 1994. Idade $\mathrm{U} / \mathrm{Pb}$ do magmatiso Uatumã no norte do Cráton Amazônico, Escudo das Guianas (Brasil): Primeiros resultados. In: SBG, Cong. Bras. Geol., 38, Camboriú, Anais, 2, p. 395-397.

Tassinari C.C.G. \& Macambira M.J.B. 2004. A evolução tectônica do Cráton Amazônico. In: Mantesso Neto V., Bartorelli A. Carneiro C.D.R., Neves B.B.B. (orgs) Geologia do continente Sul-americano: evolução da obra de Fernando Flávio Marques de Almeida. São Paulo, BECA, p. 471-485.

Tassinari C.C.G., Bittencourt J.S., Geraldes M.C., Macambira M.J.B., Lafon J.M. 2000. The Amazonian Craton. In: Cordani U.G., Milani E.J., Thomaz Filho A., Campos D.A. (eds.) Tectonic Evolution of South America, Int. Geol. Cong., 31, Rio de Janeiro, Academia Brasileira de Ciências, p. 41-96.

Truckenbrodt W., Fernandes Filho L.A., Nogueira A.C.R., Reis N.J. 2008. Stratigraphy of Paleoproterozoic Arai Group, Southern part of Guyanas Sheild, Brazil. In: IAS-SEPM, Meeting of Sedimentology, 26, BochumAlemanha. CD-Rom.

Manuscrito ID 19702 Recebido em: 08/11/2010 Aprovado em: 12/08/2011 